\title{
Maintaining the Integrity of Encrypted Data by Using the Improving Hash Function Based on GF $\left(2^{8}\right)$
}

\author{
Sahab Dheyaa Mohammed ${ }^{1}$, Abdul Monem S. Rahma ${ }^{2,}$ \\ Taha Mohammed Hasan ${ }^{3}$ \\ ${ }^{1}$ University of Information Technology and Communications, Baghdad, Iraq \\ ${ }^{2}$ Imam Ja'afar Al-Sadiq University, Computer Engineering Tech., Baghdad, Iraq \\ ${ }^{3}$ University of Diyala, College of Science, Diyala, Iraq
}

\begin{abstract}
The issue of protecting the information from penetration has become an important issue. The system that depends on the encryption ensures the confidentiality of the information non-disclosure of sensitive information but does not ensure the integrity of data from destruction and change. In this paper, a proposed system is designed to protect the confidentiality and integrity of data from penetration, disclosure, and destruction. The proposed system based on the polynomial numbers of GF $\left(2^{8}\right)$ is achieved by improving the encryption approach using the idea of the magic square and the linear equation system also uses improving the digital signature method for ensuring that data is not changed or modified. The system has higher encryption and decryption throughput $(548.924 \mathrm{~Kb} / \mathrm{sec}),(548.924 \mathrm{~Kb}$ /sec) and acceptable value 0.759294 of the randomness data according to the NIST randomness tests as well as a high confusion and diffusion in cipher text based on the ratio of Avalanche effect test.
\end{abstract}

Keywords - Gaussian Elimination, hash function, integrity, Magic Square, Finite Field.

DOI: $10.18421 /$ TEM93-57

https://doi.org/10.18421/TEM93-57

Corresponding author: Sahab Dheyaa Mohammed, University of Information Technology and

Communications, Baghdad, Iraq

Email: sahab7dia@gmail.com

Received: 29 April 2020.

Revised: 11 August 2020.

Accepted: 17 August 2020.

Published: 28 August 2020.

(cc) BY-Nc-ND (C) 2020 Sahab Dheyaa Mohammed, Abdul Monem S. Rahma \& Taha Mohammed Hasan; published by UIKTEN. This work is licensed under the Creative Commons Attribution-NonCommercial-NoDerivs 4.0 License.

The article is published with Open Access at www.temjournal.com

\section{Introduction}

The cryptographic systems are a suitable solution for protecting data through the transition. Such systems have ability to guarantee both confidentiality and integrity of sensitive data, and also against unauthorized modifying data. So, it is needed to be careful when building a cryptographic system on top of outsourced cloud storage services [1].

Several methods have been designed for remote data integrity verifying protocols, and these methods are dealing with the encrypted text integrity or plain text integrity. The problem of encrypted data is when performed the computing and manipulation of this encrypted data. Alternatively, data must be anonymized for enhancing privacy. Anonymization indicates to a privacy reservation technique to make the data valueless to unauthorized access except for the data owner.

Hiding, hashing, permutation, shift, substitution, and truncation are some of the traditional techniques to obscure data [2].

Modern cryptography methods depend on several subjects of mathematics, such as number theory, rings, fields and groups, information theory, probability theory, and statistics [3].

The algorithms of cryptographic are categorized into several forms: Symmetric, Asymmetric encryption, and Data integrity algorithms. Symmetric encryption is utilized for encrypting the plaintext of streams or blocks for any data size. Asymmetric encryption is utilized for encrypting small data unit, such as the values of hash function. Data integrity algorithms are utilized for preserving the data blocks from the protocols of authentication and alteration [4].

\subsection{Gaussian Elimination}

System of linear equations is a set of equations that are linear depending on the same set of variables. Speed and accuracy are important factors for exact 
solution of linear equations. There are two categories of linear equation methods: direct and indirect [5].

The two categories include several methods for solving equations, such as elimination approaches. One of these approaches is the Gaussian elimination which is a direct method [6].

Indirect approaches are basically repeated ways that are useful because they require a little number of multiplication steps against large computation operations. When the linear equation method is studied, one of the requirements to be understood are the matrices operations [7].

One of the standard methods for solving linear equations is the Gaussian elimination. The Gaussian elimination is useds to get the solution of equations, gain the determinant, concluding the rank of the coefficient matrix. The Gaussian elimination is categorised by two stages, forward and backward.

Forward stage: Unknowns are eliminated by changing the elements of equations and put up as an echelon form. The backward stage is dependent on the back substitution process by a reduced upper triangular method resulting in a solution of the equation [8].

\subsection{Hash Function}

The technique of Hashing utilizes a variable-length message as Input and produces a fixed-length and unique string. It is extremely hard to hold a reverse process to the original message. Where, the hashing mechanism that represents one of secure ways in cryptography uses a hash function and generates the hash values [9].

Generally, the hash functions include several steps: Firstly, divide the input message into blocks; Secondly, for the first block, calculate the hash value of a fixed size. Thirdly, obtain the hash for the second block, and add it to the previous output; Finally, repeat these steps until all blocks are calculated [10].

The hash algorithm is the algorithm that changes the text or message into a set of symbols and letters to protect it from access to the plaintext or retrieve it by the attackers of the system. The oneway property is used by hashing algorithms which makes it difficult or even impossible to retrieve the original text from the value generated by this algorithm. You can use this type of algorithm to create an electronic signature that achieves the authenticity of the data, that is, it is from a reliable source. Hash algorithms consist of a procedure that converts big data into small data or from data of variable size to data of a fixed size as shown in Figure 1. The data generated by this type of algorithm are called hash codes [11].

One-way hash algorithms is one of the most important algorithms used in cryptography where it is used to solve the problems of integrity and it is considered an alternative to the encryption algorithm authentication code for the message that does not need to have a key in the encryption process where the result is a hash value that cannot retrieve the original data [12].

\section{Related Work}

The authors (2006) proposed a work dealing with the vector space dimension of regular -diagonal magic squares. They proved the result of the evenorder regular magic squares were singular. Odd-order regular magic squares that have singular and nonsingular are generated from matrix theoretic constructions [13]. The authors (2015) suggest a work that presents an approach for linear equations. The purpose of this work was analyzing several methods of elimination of linear equations and computing the efficiency of the Gauss elimination and the Gauss Jordan approach, to find their relative significance and importance in the range of symbolic and numeric computations [14].

In (2012), Nitin Pandey proposed an approach of encryption and decryption depending on the construction of magic rectangles and RSA encryption. The proposed approach built different single even magic of even ordered rectangles that don't accept division by 4 , where the summation of every row and column values is equal. This developed approach works on maximizing the complexity and randomness of the cipher-text, additionally, it requires more time for the implementation process [15]. In the same year, M.A.Noaman uses a hash function (MD5) by generating an authentication key form as an authentication code (MAC). The aims of the performance of this algorithm is to provide privacy in the application to execute the MD5 for the data integrity checking method and to make sure of the valid state of the data in the information system [16]. E. Noroozi, S.Daud and A. Sabouhi ( 2013) this paper presents a new method in generating smallsized digital signature by using a hash algorithm, where the reducing $4 \%$ of the size of the original file in plaintext mean 1600 bytes. This method contributes to enhancing the verification of the signature and improving all the speed and time of the operation [17].

\section{Proposed Methodology}

The proposed cryptographic system contributes to improving the privacy and data integrity received from trusted authorities using an encryption method based on the linear equation system in addition to creating a method for digital signature based on the hash function to ensure that data is not changed or modified, which provides additional security features.

The proposed system includes two operations; the first is the plain-text encryption process. The second 
process is sending the encrypted text associated with the digital signature based on the hash function. Figure 1, illustrates the encryption and decryption operations of the proposed system.

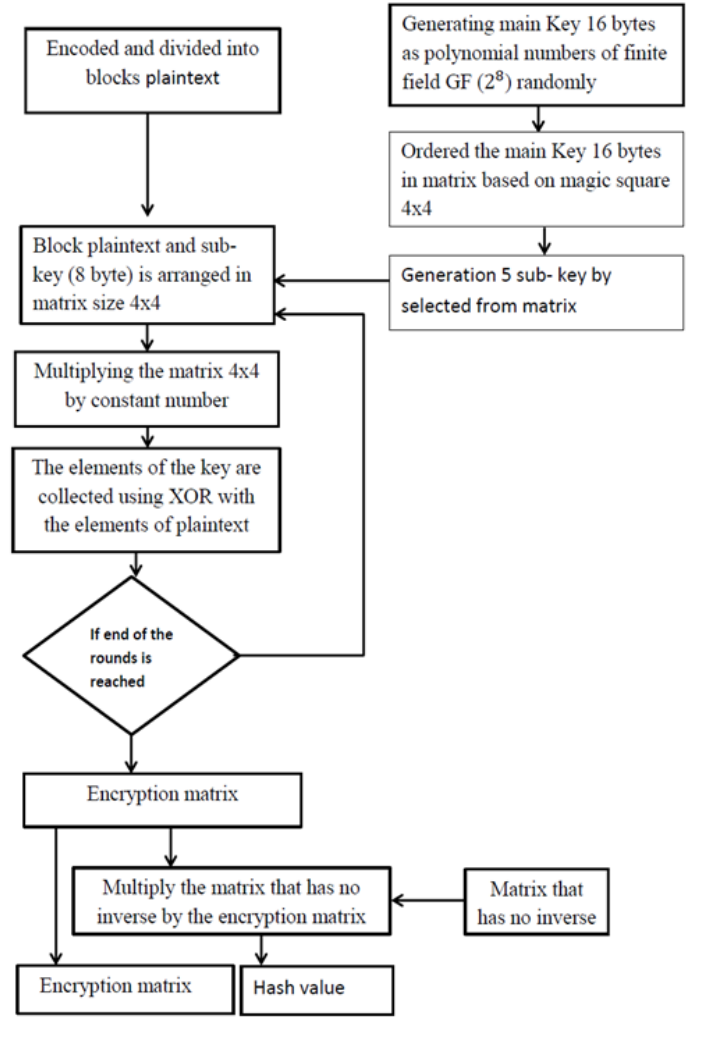

a.The block diagram of encryption operation

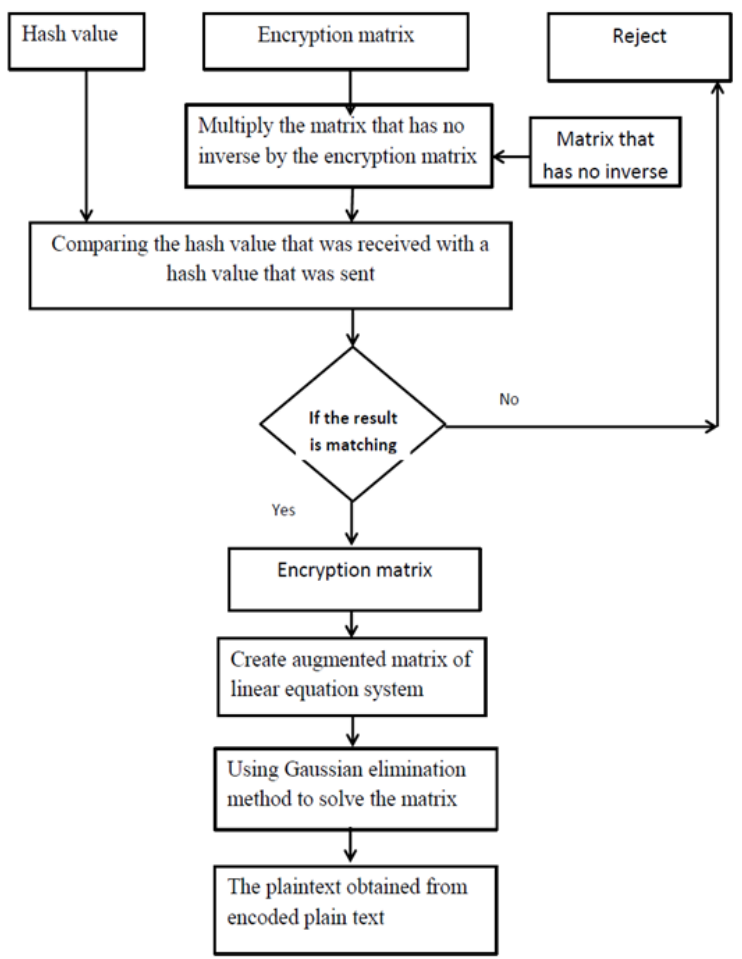

b. the block diagram of decryption operation

Figure 1. The encryption and decryption operations of the proposed system.
The implementation of the proposed system is executed in two phases as the following:

\subsection{Encryption Phase}

Before entering the encryption process, the plain text is encoded and divided into blocks, each block has a size of 8 bytes. The encoding process is done by encoding all characters using the ASCII code for plain text between 1 and 255 bytes where each character represents a byte of the polynomial number as a finite field of GF $\left(2^{8}\right)$. Figure 2. illustrates the encoding process of a sample of the characters.

\begin{tabular}{|c|c|c|c|c|c|c|c|c|c|}
\hline plaintext & $p 1$ & $p 2$ & $p 3$ & $p 4$ & $p 5$ & $p 5$ & $p 6$ & $p 7$ & $p 8$ \\
\hline $\begin{array}{c}\text { ASCII } \\
\text { COD }\end{array}$ & P1 & P2 & P3 & P4 & P5 & P5 & P6 & P7 & P8 \\
\hline
\end{tabular}

Figure 2. The encoding sample of the characters

The characters are arranged and numbered in a single array.

Then, the steps of the encryption process are performed in five-round where each round contents the following steps:

Step 1: The encoded block (in the first round) or previous encryption block and sub-key element (8 bytes) are arranged in matrix $\left[\boldsymbol{L}_{\boldsymbol{i}}\right]$ size $4 \times 4$. Figure 2 . shows the matrix including elements of encoded plain text and sub-key elements.

$\left[\boldsymbol{L}_{\boldsymbol{i}}\right]=\quad$\begin{tabular}{|l|l|l|l|}
\hline $\mathrm{K} 1$ & $\mathrm{~K} 2$ & $\mathrm{~K} 3$ & $\mathrm{P} 1$ \\
\hline $\mathrm{K} 4$ & $\mathrm{~K} 5$ & $\mathrm{~K} 6$ & $\mathrm{P} 2$ \\
\hline $\mathrm{K} 7$ & $\mathrm{~K} 8$ & $\mathrm{P} 3$ & $\mathrm{P} 4$ \\
\hline P5 & P6 & P7 & P8 \\
\hline
\end{tabular}

Step 2: multiplying the matrix $\left(L_{i}\right)$ by constant number 245 based on Equation 1. using an irreducible polynomial $\left(x^{\mathbf{8}}+\boldsymbol{x}^{\mathbf{4}}+\boldsymbol{x}^{\mathbf{3}}+x+1\right)$. The results represent new elements of matrix $\left(\boldsymbol{C}_{\boldsymbol{i}}\right) 4 \times 4$ shown in Figure 3.

$$
C_{i}=\left(L_{i} \cdot x\right) \operatorname{Mod} M
$$

Where:

$\boldsymbol{C}_{\boldsymbol{i}}=$ the elements of new encoded matrix $4 \times 4$.

$\boldsymbol{L}_{\boldsymbol{i}}=$ the elements of encoded matrix $4 \times 4$.

$\boldsymbol{x}=$ constant number (245).

$\boldsymbol{M}=$ irreducible polynomial $\left(x^{8}+x^{4}+x^{3}+x+1\right)$.

$$
\left[C_{i}\right]=
$$

\begin{tabular}{|c|c|c|c|}
\hline Y1 & Y2 & Y3 & B1 \\
\hline Y4 & Y5 & Y6 & B2 \\
\hline Y7 & Y8 & B3 & B4 \\
\hline B5 & B6 & B7 & B8 \\
\hline
\end{tabular}

Figure 3. Shows the new matrix of plain text and key 
Step 3: The matrix $\left(L_{i}\right) 4 \times 4$ includes 8 bytes of encoded plaintext and 8 bytes of the sub-key (that significant from the main key of size 40 bytes had been selected randomly from 1-255). To be performed the encryption process, must the elements of the sub-key are collected using XOR with the elements of plaintext for each row and column of the matrix in the form of linear equations. So, the following equations will be calculated based on performed experiments, that only are used (first, second, third and fourth) rows and (first, second and the fourth) columns to be summed up .Also, the main diagonals are used in addition to rows and columns.

$\begin{array}{lll}\mathrm{Y} 1+\mathrm{Y} 2+\mathrm{Y} 3+\mathrm{B} 1 & =\mathrm{S} 1 & {[2]} \\ \mathrm{Y} 4+\mathrm{Y} 5+\mathrm{Y} 6+\mathrm{B} 2 & =\mathrm{S} 2 & {[3]} \\ \mathrm{Y} 7+\mathrm{Y} 8+\mathrm{B} 3+\mathrm{B} 4 & =\mathrm{S} 3 & {[4]} \\ \mathrm{B} 5+\mathrm{B} 6+\mathrm{BP} 7+\mathrm{B} 8 & =\mathrm{S} 4 & {[5]} \\ \mathrm{Y} 1+\mathrm{Y} 4+\mathrm{Y} 7+\mathrm{B} 5 & =\mathrm{S} 5 & {[6]} \\ \mathrm{Y} 2+\mathrm{Y} 5+\mathrm{Y} 8+\mathrm{B} 6 & =\mathrm{S} 6 & {[7]} \\ \mathrm{B} 1+\mathrm{B} 2+\mathrm{B} 4+\mathrm{B} 8 & =\mathrm{S} 7 & {[8]} \\ \mathrm{Y} 1+\mathrm{Y} 5+\mathrm{B} 3+\mathrm{B} 8 & =\mathrm{S} 8 & {[9]}\end{array}$

The summations of the 2-9 equations represent the results of the 8 bytes of cipher text [S1, S2, S3, S4, $\mathrm{S} 5, \mathrm{~S} 6, \mathrm{~S} 7, \mathrm{~S} 8]$.

Step 3: The previous steps repeat five rounds, the output of each step being input for the next step. So, the output of the last round is arranged in matrix (S) $3 \times 3$. The last element (S9) is added to the matrix as a salt to fill in the matrix as shown in Figure 4.:

$\mathrm{S}=\quad$\begin{tabular}{|l|l|l|}
\hline $\mathrm{S} 1$ & $\mathrm{~S} 2$ & $\mathrm{~S} 3$ \\
\hline $\mathrm{S} 4$ & $\mathrm{S5}$ & $\mathrm{S6}$ \\
\hline $\mathrm{S} 7$ & $\mathrm{~S} 8$ & $\mathrm{~S} 9$ \\
\hline
\end{tabular}

Figure 4. Shows the encrypted matrix of the last round

Step 4: in this step, any matrix that has no inverse is chosen to generating a one-way hash algorithm. Figure 5, shows the matrix has no inverse because the determinant of this matrix is equal to 0 .

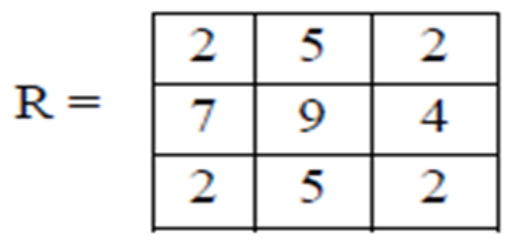

Figure 5. Shows the matrix has no inverse

So we multiply the matrix that has no inverse by the encryption matrix and the remainder of the division is a hash value.

The sender of the message calculates the hash value of the encryption text using the equation (10) that all operation are using polynomial operation and irreducible polynomial $\left(x^{8}+x^{4}+x^{3}+x+1\right)$ in the following.

$$
[\mathbf{V}]=[\mathbf{S}] \cdot[\mathbf{R}]
$$

\section{Where:}

$[\mathrm{V}]=$ the matrix of hash value

$[\mathrm{S}]=$ the matrix of encrypted data

$[R]=$ matrix has no inverse

Then, hash value $[\mathrm{V}]$ and Encryption matrix $[\mathrm{S}]$ have been gathered and sent to the receiver.

\subsection{Keys Generation}

This system creates of 16-bytes main key $N_{i}$ by one of the random number generation algorithms as nonzero elements. Any byte is a set in the finite field GF $\left(2^{8}\right)$. Then, it is ordered in the matrix in size $4 \times 4$ bytes based on the form of the magic square fourth order $4 \times 4$ is shown in Figure 6. Figure 7. show the order of key values in the matrix $(4 \times 4)$.

\begin{tabular}{|l|l|l|l|}
\hline 1 & 2 & 16 & 15 \\
\hline 13 & 14 & 4 & 3 \\
\hline 12 & 7 & 9 & 6 \\
\hline 8 & 11 & 5 & 10 \\
\hline
\end{tabular}

Figure 6. Magic square fourth order $4 \times 4$

\begin{tabular}{|l|l|l|l|}
\hline N1 & N2 & N16 & N15 \\
\hline N13 & N14 & N4 & N3 \\
\hline N12 & N7 & N9 & N6 \\
\hline N8 & N11 & N5 & N10 \\
\hline
\end{tabular}

Figure 7. Show the order of key values in the matrix $4 \times 4$

Each round has 8 bytes of different Sub-Key that derived from the main key; where the sub-key of each round is assigned of the one row and one column of elements except the fifth round which is assigned the two diagonals of the elements. The subkeys of the five rounds are calculated in the following.

1. Sub-Key of first round $=$ N1, N2, N16, N15, N1, N13, N12, N8.

2. Sub-Key of second round $=$ N13, N14, N4, N3, N2, N14, N7, N11.

3. Sub-Key of third round $=$ N12, N7, N9, N6, N16, N4, N9, N5.

4. Sub-Key of fourth round $=\mathrm{N} 8+\mathrm{N} 11+\mathrm{N} 5+\mathrm{N} 10$, N15, N3, N6, N16.

5. Sub-Key of fifth round $=$ N1, N14, N9, N10, N15, N4, N7, N8. 
The Encryption algorithm of proposed method is:

\begin{tabular}{|c|c|}
\hline \multicolumn{2}{|c|}{$\begin{array}{l}\text { Input : block ( } 8 \text { bytes) of encoded original data } \\
\text { Output : block ( } 9 \text { bytes) of cipher text }\end{array}$} \\
\hline Step 1 & $\begin{array}{l}\text { The encoded block and sub-key element } \\
\text { are arranged in matrix }\left[\boldsymbol{L}_{\boldsymbol{i}}\right] \text { size } 4 \times 4 \text {. } \\
{\left[\boldsymbol{L}_{\boldsymbol{i}}\right]=\boldsymbol{K}_{\boldsymbol{j}},\left[\boldsymbol{L}_{\boldsymbol{i}}\right]=\boldsymbol{P}_{\boldsymbol{j}} \quad \text { where: }} \\
\mathbf{i}=(\mathbf{1}, \mathbf{2} \ldots \mathbf{1 6}), \boldsymbol{j}=(\mathbf{1}, \mathbf{2} \ldots \mathbf{8})\end{array}$ \\
\hline Step 2 & $\begin{array}{l}\text { multiplying the matrix }\left(L_{i}\right) \text { by constant } \\
\text { number } 245 \\
\boldsymbol{C}_{\boldsymbol{i}}=\left(\boldsymbol{L}_{\boldsymbol{i}} \cdot \boldsymbol{x}\right) \boldsymbol{M o d} \boldsymbol{M}\end{array}$ \\
\hline Step 3 & 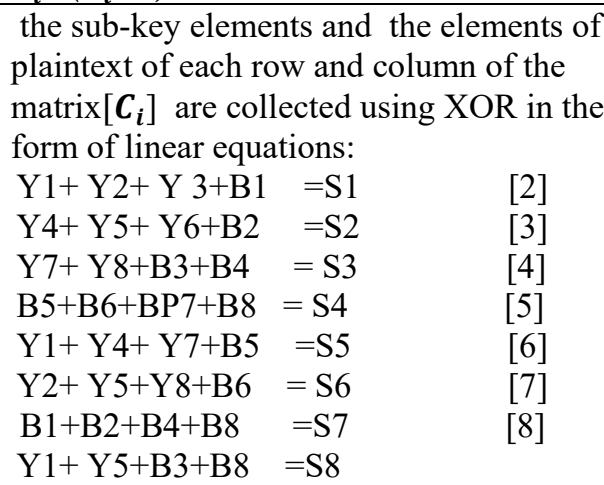 \\
\hline Step 4 & repeat the three steps above five-times \\
\hline Step 5 & $\begin{array}{l}\text { the output of the last round is arranged in } \\
\text { matrix }[\mathrm{S}] 3 \times 3 \\
{\left[S_{i}\right]=\{\mathrm{S} 1, \mathrm{~S} 2, \mathrm{~S} 3, \mathrm{~S} 4, \mathrm{~S} 5, \mathrm{~S} 6, \mathrm{~S} 7, \mathrm{~S} 8, \mathrm{~S} 9\}} \\
\text { where }: \mathrm{S} 9=\text { is a salt }\end{array}$ \\
\hline Step 6 & $\begin{array}{l}\text { Generating a one-way hash algorithm by } \\
\text { chosen not inverse matrix }[\mathrm{R}] \text { and } \\
\text { multiplying by the encryption matrix }[\mathrm{S}] \text {. } \\
{[\mathrm{V}]=[\mathrm{S}] .[\mathrm{R}]}\end{array}$ \\
\hline
\end{tabular}

\subsection{Decryption Phase}

The decryption phase is performed by reversing the steps of the encryption phase. The last round of decryption phase is illustrated as the following.

Step 1: Upon receiving the encrypted message and the hash value by the recipient, the receiver ensures that the message is integrated and has not been changed. The same procedures of equation (10) are used in the calculation of the hash value performed on the sender side and comparing it with the hash value that is received.

$$
[\mathrm{V}]=[S] \cdot[R]
$$

Then the recipient compares the hash value that was received with a hash value that was sent. If the result has corresponded, the encrypted message is valid and did not expose to change and update.

Step 2: Before the decryption process, we need to know the last values $\left(\boldsymbol{Y}_{\boldsymbol{i}}\right)$ of the sub-key by using the following equation 1 :

$$
Y_{i}=\left(K_{i} \cdot P\right) \bmod \mathbf{M}
$$

$Y_{i}=$ last values of sub-key

$K_{i}=$ last original sub-key

$P=$ the constant number

$\mathrm{M}=$ irreducible polynomial $\left(x^{8}+x^{4}+x^{3}+x+1\right)$.

Then, create Augmented matrix of linear equation system of encryption matrix [S] based on equations $2, \ldots ., 9$ and arrange the summation column of the Augmented matrix based on the elements of

\begin{tabular}{|c|c|c|c|c|c|c|c|c|c|c|c|c|c|c|c|c|}
\hline $\mathrm{l}$ & & \begin{tabular}{ll|}
$\mathrm{Y} 3$ \\
\end{tabular} & $\mathrm{Bl}$ & $\mathrm{Y4}$ & 15 & $\mathrm{Y} 6$ & B2 & & Y8 & $\bar{B}$. & BA & $B 5$ & B6 & & & SCXI \\
\hline 1 & 1 & 1 & 1 & 0 & 0 & $\overline{0}$ & 0 & 0 & 0 & 0 & 0 & 0 & & 0 & & SI \\
\hline 0 & 0 & 0 & $\overline{0}$ & 1 & 1 & 1 & 1 & 0 & 0 & 0 & 0 & 0 & 0 & & & $\$ 2$ \\
\hline 0 & 0 & & 0 & 0 & 0 & 0 & 0 & 1 & 1 & 1 & 1 & 0 & 0 & & & 53 \\
\hline 0 & & & 0 & 0 & 0 & 0 & 0 & 0 & 0 & 0 & 0 & 1 & 1 & & & $\$ 4$ \\
\hline 1 & & & 0 & 1 & 0 & $\overline{0}$ & 0 & 1 & 0 & 0 & 0 & 1 & & & & 55 \\
\hline 0 & & & $\overline{0}$ & $\overline{0}$ & 1 & $\overline{0}$ & 0 & 0 & 1 & $\overline{0}$ & $\overline{0}$ & 0 & & & & 56 \\
\hline 0 & & $\overline{0}$ & 1 & 0 & 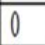 & $\overline{0}$ & & 0 & 0 & 0 & 1 & 0 & & & & 57 \\
\hline 1 & & & & 0 & & & & & $\overline{0}$ & & & & & & & 58 \\
\hline
\end{tabular}
encryption matrix $[\mathrm{S}]$ as follows:

Step 3: removing Key columns $\{1,2,3,4,5,6,7$, and 8$\}$ and rearranging of summation column as follows:

\begin{tabular}{|c|c|c|c|c|c|c|c|c|}
\hline B1 & B2 & B3 & B4 & B5 & B6 & B7 & B8 & SUM \\
\hline $\mathbf{1}$ & 0 & 0 & 0 & 0 & 0 & 0 & 0 & S1 \\
\hline 0 & $\mathbf{1}$ & 0 & 0 & 0 & 0 & 0 & 0 & S2 \\
\hline 0 & 0 & $\mathbf{1}$ & $\mathbf{1}$ & 0 & 0 & 0 & 0 & $\mathbf{S 3}$ \\
\hline 0 & 0 & 0 & 0 & $\mathbf{1}$ & $\mathbf{1}$ & $\mathbf{1}$ & $\mathbf{1}$ & $\mathbf{S 4}$ \\
\hline 0 & 0 & 0 & 0 & $\mathbf{1}$ & 0 & 0 & 0 & $\mathbf{S 5}$ \\
\hline 0 & 0 & 0 & 0 & 0 & $\mathbf{1}$ & 0 & 0 & S6 \\
\hline $\mathbf{1}$ & $\mathbf{1}$ & 0 & $\mathbf{1}$ & 0 & 0 & 0 & $\mathbf{1}$ & $\mathbf{S 7}$ \\
\hline 0 & 0 & $\mathbf{1}$ & 0 & 0 & 0 & 0 & $\mathbf{1}$ & $\mathbf{S 8}$ \\
\hline
\end{tabular}

Step 4: using the Gaussian elimination method to solve the matrix and depending on the operation of the finite field.

\begin{tabular}{|c|c|c|c|c|c|c|c|c|}
\hline B1 & B2 & B3 & B4 & B5 & B6 & B7 & B8 & \\
\hline 1 & 0 & 0 & 0 & 0 & 0 & 0 & 0 & B1 \\
\hline 0 & $\mathbf{1}$ & 0 & 0 & 0 & 0 & 0 & 0 & B2 \\
\hline 0 & 0 & $\mathbf{1}$ & 0 & 0 & 0 & 0 & 0 & B3 \\
\hline 0 & 0 & 0 & $\mathbf{1}$ & 0 & 0 & 0 & 0 & B4 \\
\hline 0 & 0 & 0 & 0 & $\mathbf{1}$ & 0 & 0 & 0 & $\mathbf{B 5}$ \\
\hline 0 & 0 & 0 & 0 & 0 & $\mathbf{1}$ & 0 & 0 & $\mathbf{B 6}$ \\
\hline 0 & 0 & 0 & 0 & 0 & 0 & $\mathbf{1}$ & 0 & $\mathbf{B 7}$ \\
\hline 0 & 0 & 0 & 0 & 0 & 0 & 0 & $\mathbf{1}$ & $\mathbf{B 8}$ \\
\hline
\end{tabular}

Then, the encryption block of the next round can be obtained from the equation (12) as follow:

$$
P_{i}=B_{i} \cdot x^{-1} \operatorname{Mod} \mathbf{m}
$$

Where

$\boldsymbol{P}_{\boldsymbol{i}}=$ encryption block $\left(\boldsymbol{S}_{\boldsymbol{i}}\right)$ of next round

$\boldsymbol{B}_{\boldsymbol{i}}=$ new encoded plain text

$x^{-1}=$ reverse the constant number

$\mathbf{m}=$ irreducible polynomial $\left(x^{8}+x^{4}+x^{3}+x+1\right)$.

Where: 
Finally, the encoded plaintext of the last round is obtained by the same decryption way of the previous rounds and then, decoded to gain plaintext by using the ASCII code table.

The Decryption algorithm of proposed method is:

\begin{tabular}{|c|c|c|}
\hline \multicolumn{3}{|c|}{$\begin{array}{l}\text { Input : block ( } 8 \text { bytes) of encoded original data } \\
\text { Output : block ( } 9 \text { bytes) of cipher text }\end{array}$} \\
\hline Step 1 & $\begin{array}{l}\text { The encoded block and sul } \\
\text { are arranged in matrix }\left[L_{i}\right. \\
{\left[L_{i}\right]=K_{j},\left[L_{i}\right]=P_{j}} \\
\mathrm{i}=(1,2 \ldots 16), j=(1,2 \ldots .8)\end{array}$ & ement \\
\hline Step 2 & $\begin{array}{l}\text { multiplying the matrix }\left(L_{i}\right) \\
\text { number } 245 \\
\qquad \boldsymbol{C}_{i}=\left(\boldsymbol{L}_{i} \ldots \text {. v }\right) \text { Mod }\end{array}$ & \\
\hline Step 3 & $\begin{array}{l}\text { the sub-key elements and t1 } \\
\text { plaintext of each row and co } \\
\text { matrix }\left[C_{i}\right] \text { are collected usi } \\
\text { form of linear equations: } \\
\text { Y1+ Y2+Y 3+B1 =S1 } \\
\mathrm{Y} 4+\mathrm{Y} 5+\mathrm{Y} 6+\mathrm{B} 2=\mathrm{S} 2 \\
\mathrm{Y} 7+\mathrm{Y} 8+\mathrm{B} 3+\mathrm{B} 4=\mathrm{S} 3 \\
\mathrm{~B} 5+\mathrm{B} 6+\mathrm{BP} 7+\mathrm{B} 8=\mathrm{S} 4 \\
\mathrm{Y} 1+\mathrm{Y} 4+\mathrm{Y} 7+\mathrm{B} 5=\mathrm{S} 5 \\
\mathrm{Y} 2+\mathrm{Y} 5+\mathrm{Y} 8+\mathrm{B} 6=\mathrm{S} 6 \\
\mathrm{~B} 1+\mathrm{B} 2+\mathrm{B} 4+\mathrm{B} 8=\mathrm{S} 7 \\
\mathrm{Y} 1+\mathrm{Y} 5+\mathrm{B} 3+\mathrm{B} 8=\mathrm{S} 8\end{array}$ & $\begin{array}{l}\text { nts of } \\
\text { the } \\
\text { in the } \\
{[2]} \\
{[3]} \\
{[4]} \\
{[5]} \\
{[6]} \\
{[7]} \\
{[8]}\end{array}$ \\
\hline Step 4 & repeat the three steps above & \\
\hline Step 5 & $\begin{array}{l}\text { the output of the last round } \mathrm{i} \\
\text { matrix }[\mathrm{S}] 3 \times 3 \\
{\left[S_{i}\right]=\{\mathrm{S} 1, \mathrm{~S} 2, \mathrm{~S} 3, \mathrm{~S} 4, \mathrm{~S} 5, \mathrm{~S} 6, \mathrm{~S}} \\
\text { where : } \mathrm{S} 9=\text { is a salt }\end{array}$ & in \\
\hline Step 6 & $\begin{array}{l}\text { Generating a one-way hash } \\
\text { chosen not inverse matrix [R } \\
\text { by the encryption matrix [S] } \\
\qquad[\mathrm{V}]=[\mathrm{S}] .[\mathrm{R}]\end{array}$ & $\begin{array}{l}\text { by } \\
\text { tiply }\end{array}$ \\
\hline
\end{tabular}

\section{Results and Analysis}

The proposed system aims to implement a new encryption method and achieve the integrity and confidentiality of sensitive data that is sent away, which is tested through various techniques related to the encryption data to prove the effectiveness of the proposed algorithm

The measures of system results such as the Time criteria, Randomness test and Avalanche effect test are illustrated in the following.

Various file sizes of encrypted data and original data were used for testing. Where a comparison algorithms DES, original AES (Rijandar) with the proposed system was performed by testing the execution time of the algorithms on the same device that uses to the proposed system. Table 1. and 2 . show the comparison between the other algorithms of execution times (in seconds) with various samples size in $(\mathrm{Kb})$. The execution time is used to computing the throughput of the encrypted and decryption algorithms.

Table 1. The Comparison of encryption throughput (Kb/sec)

\begin{tabular}{|c|c|c|c|}
\hline File Size (Kb) & DES 56 & $\begin{array}{c}\text { AES } \\
\text { (Rijandar) }\end{array}$ & $\begin{array}{c}\text { proposed } \\
\text { system }\end{array}$ \\
\hline 255 & 1.612 & 0.973 & 0.710 \\
\hline 2802.01 & 8.239 & 6.953 & 4.139 \\
\hline 6591.52 & 16.048 & 13.281 & 10.613 \\
\hline 9963.97 & 22.177 & 18.753 & 15.113 \\
\hline$\sum 19612.5$ & 48.076 & 39.960 & 30.575 \\
\hline $\begin{array}{c}\text { Average } \\
4903.125\end{array}$ & 12.019 & 9.99 & 7.64375 \\
\hline $\begin{array}{c}\text { Encryption } \\
\text { throughput } \\
\text { (Kb/sec) }\end{array}$ & 407.948 & 490.804 & 641.456 \\
\hline
\end{tabular}

Table 2. The Comparative of decryption throughput $(\mathrm{Kb} / \mathrm{sec})$

\begin{tabular}{|c|c|c|c|}
\hline File Size (Kb) & DES 56 & $\begin{array}{c}\text { AES } \\
\text { (Rijandar) }\end{array}$ & $\begin{array}{c}\text { proposed } \\
\text { system }\end{array}$ \\
\hline 255 & 1.946 & 1.365 & 0.953 \\
\hline 2802.01 & 8.743 & 7.371 & 4.893 \\
\hline 6591.52 & 16.487 & 13.642 & 12.625 \\
\hline 9963.97 & 22.598 & 19.189 & 17.258 \\
\hline$\sum 19612.5$ & 49.774 & 41.567 & 35.729 \\
\hline $\begin{array}{c}\text { Average } \\
4903.125\end{array}$ & 12.443 & 10.391 & 8.93225 \\
\hline $\begin{array}{c}\text { decryption } \\
\text { throughput } \\
\text { (Kb /sec) }\end{array}$ & 394.046 & 471.862 & 548.924 \\
\hline
\end{tabular}

In the tables above it can be noticed that the proposed system requires less time than DES, AES algorithm in encryption and decryption operations. Because the number of rounds in proposed system are less than the numbers rounds in the other algorithms. The randomness tests are very important to know if there is a deviation between plaintext/cipher text bits and define the degree of random form for the cipher text. The proposed 
system results are shown an accepted and suitable degree according to the NIST randomness test. Where a set of experimental results was tested for all parts of the system displayed in the following Table 3.

Table 3. The NIST Statistical tests for encrypted results

\begin{tabular}{|c|c|c|c|c|c|}
\hline & Statistical Tests & $\begin{array}{l}\text { Input } \\
\text { Size (n) }\end{array}$ & $\begin{array}{c}\text { P-Value } \\
\text { Proposed } \\
\text { system }\end{array}$ & $\begin{array}{l}\text { P. } \\
\text { Value } \\
\text { DES }\end{array}$ & $\begin{array}{l}\text { The } \\
\text { results }\end{array}$ \\
\hline \multirow[t]{4}{*}{1} & \multirow{3}{*}{$\begin{array}{l}\text { Frequency (Monobit) } \\
\text { Test }\end{array}$} & 10000 & 0.984043 & 0.995132 & pass \\
\hline & & 50000 & 0.452461 & 0.323456 & pass \\
\hline & & 100000 & 0.627166 & 0.734372 & pass \\
\hline & Arerage of P-ralue & & 0.68789 & 0.690987 & pass \\
\hline \multirow[t]{4}{*}{2} & \multirow{3}{*}{$\begin{array}{l}\text { Block Frequency } \\
(m 11=8)\end{array}$} & 10000 & 0.345667 & 0.255348 & pass \\
\hline & & 50000 & 0.322346 & 0.254536 & pass \\
\hline & & 100000 & 0.734567 & 0.278271 & pass \\
\hline & Arerage of P-ralue & & 0.467527 & 0.262719 & pass \\
\hline \multirow[t]{4}{*}{3} & \multirow{3}{*}{$\begin{array}{l}\text { Approximate } \\
\text { Entropy Test } \mathrm{m}=3\end{array}$} & 10000 & 0.923461 & 0.708696 & pass \\
\hline & & 50000 & 0.967897 & 0.677355 & pass \\
\hline & & 100000 & 0.961988 & 0.898384 & pass \\
\hline & Average of $\mathrm{P}$-ralue & & 0.951115 & 0.761478 & pass \\
\hline \multirow[t]{4}{*}{4} & \multirow{3}{*}{$\begin{array}{l}\text { Linear Complexity } \\
\text { Test }(M=100)\end{array}$} & 10000 & 0.639239 & 0.364553 & pass \\
\hline & & 50000 & 0.477616 & 0.471138 & pass \\
\hline & & 100000 & 0.713489 & 0.535714 & pass \\
\hline & Average of P-ralue & & 0.610115 & 0.457135 & pass \\
\hline \multirow[t]{4}{*}{5} & \multirow{3}{*}{ Runs Test } & 10000 & 0.518737 & 0.445712 & pass \\
\hline & & 50000 & 0.831028 & 0.534672 & pass \\
\hline & & 100000 & 0.928116 & $0.68258 ?$ & pass \\
\hline & Arerage of $\mathrm{P}$-ralue & & 0.759294 & 0.554322 & pass \\
\hline & \multicolumn{2}{|c|}{ Total Arerages of P-ralue } & 0.695188 & 0.545328 & \\
\hline
\end{tabular}

Where the randomness test results of the proposed system are acceptable and have high averages of Pvalues, where a $\mathrm{P}$-value for a test is equal to one, and then the value will be ideal randomness. A P-value of zero refers to that the value is completely nonrandom.

The Avalanche Effect test is an important test of the cipher algorithm. This test is based on a little change in the plain text, and then we calculate the outputs of the bits in the cipher text.

In other words, any change in one bit of the plain text or key must be a large change in the bits of the cipher text. Avalanche effect is calculated by using the following equation:

$\mathrm{AE}=\frac{\text { Number of Changed Bits in Cipher text }}{\text { Total number of bits in cipher text }} * 100$

To evaluate the proposed system on a variety of bits that change by one-bit in plaintext with remains the key bits constant or change one-bit of the key bits with remains plaintext bits constant. Table 4. shows the test of two samples that represent the outputs of the proposed system.

\begin{tabular}{|c|c|c|c|c|c|}
\hline No. & Keys & input & Output & $\mathbf{A E}$ & $\begin{array}{c}\text { AE } \\
\text { Test } \\
\%\end{array}$ \\
\hline \multirow[t]{2}{*}{1} & $\begin{array}{c}32,161,24 \\
111,255,15 \\
8,62,21\end{array}$ & $\begin{array}{l}65,98,115 \\
, 116,114, \\
97,99,116\end{array}$ & $\begin{array}{c}99,105,11 \\
2,104,101 \\
, 60,182 \\
238,87\end{array}$ & \multirow[t]{2}{*}{0.55} & \multirow[t]{2}{*}{$55 \%$} \\
\hline & $\begin{array}{c}32,161,24, \\
111,255,15 \\
8,126,21 \\
\end{array}$ & $\begin{array}{r}65,98,115 \\
, 116,114, \\
97,99,116 \\
\end{array}$ & $\begin{array}{l}31,24,13 \\
54,77,39 \\
74,40,14\end{array}$ & & \\
\hline \multirow{2}{*}{2} & $\begin{array}{c}1,107,225 \\
60,182,238 \\
, 87,227\end{array}$ & $\begin{array}{c}71,97,117 \\
, 115,115, \\
97,110\end{array}$ & $\begin{array}{c}60,182,23 \\
8,87,227, \\
239,174, \\
24,161\end{array}$ & \multirow{2}{*}{0.51} & \multirow{2}{*}{$51 \%$} \\
\hline & $\begin{array}{c}1,107,225 \\
60,182,238 \\
, 87,227\end{array}$ & $\begin{array}{c}71,97,117 \\
, 115,77,9 \\
7,110\end{array}$ & $\begin{array}{c}97,136,24 \\
2,55,187 \\
209,146 \\
106,157\end{array}$ & & \\
\hline \multicolumn{4}{|c|}{ Main percentage avalanche value } & 0.53 & $53 \%$ \\
\hline
\end{tabular}

$$
\begin{aligned}
& A E \text { Sample } 1=\frac{5+4+6+5+2+4+6+4+4}{72}=\frac{40}{72}=0.55 \\
& A E \text { Sample 2= } \frac{5+5+3+2+3+5+4+6+4}{72}=\frac{37}{72}=0.51
\end{aligned}
$$

The XOR operation is calculated between the two results of each sample to getting the summation of the numbers of different bits between these two results. The percentage average of the Avalanche value of the proposed system is approximately $53 \%$ of the different bits of cipher text. Where the acceptable ratio is $50 \%$. So our algorithm has good confusion and diffusion between the cipher text and plaintext and also between the key and the cipher text.

\section{Conclusion}

In this paper, a proposed system is designed to protect the confidentiality and integrity of data from penetration, disclosure, and destruction. The proposed system provides increasing of the substitution, permutation techniques in the encryption stage and increasing the difficulty of breaking the cipher text and gives higher encryption and decryption throughput than DES, AES algorithm . The proposed system is achieved by improving the encryption approach and digital signature method based on improving the one-way hash algorithm by using the idea of the magic square and the linear equation system in encryption and decryption stages. In addition, the initial hash value was created by the inverse matrix for ensuring that encrypted data is not changed or modified.It is recommended for the future to improve the research by increasing the size magic square $8 \times 8$ in the encryption stage in order to accommodate a larger block size of plain text and a longer key length. 


\section{References}

[1].Yun, A., Shi, C., \& Kim, Y. (2009, November). On protecting integrity and confidentiality of cryptographic file system for outsourced storage. In Proceedings of the 2009 ACM workshop on Cloud computing security (pp. 67-76).

[2].Tikore, S. V., Pradeep, K. D., \& Prakash, B. D. (2015). Ensuring the data integrity and confidentiality in cloud storage using hash function and TPA. International Journal on Recent and Innovation Trends in Computing and Communication, 3(5), 2736-2740.

[3].Perlman, R., Kaufman, C., \& Speciner, M. (2016). Network security: private communication in a public world. Pearson Education India.

[4]. Stallings, W. (2012). Cryptography and network security, principles and practice (international edition). International Journal of Engineering \& Computer Science, 1(01), 121-136.

[5].Hsu, C. W., \& Lin, C. J. (2002). A comparison of methods for multiclass support vector machines. IEEE transactions on Neural Networks, 13(2), 415-425.

[6].Issa, R. I. (1986). Solution of the implicitly discretised fluid flow equations by operator-splitting. Journal of computational physics, 62(1), 40-65.

[7].Grcar, J. F. (2011). How ordinary elimination became Gaussian elimination. Historia Mathematica, 38(2), 163-218.

[8].Winkler, F. (2012). Polynomial algorithms in computer algebra. Springer Science \& Business Media.

[9].P. V. Rao, S. G. Rao, P. C. Reddy, G. R. Sakthidharan, and Y. M. Kumar,( 2019). Improve the integrity of data using hashing algorithms.Int. J. Innov. Technol. Explor. Eng., 8(7), 2018-2023.
[10]. European Data Protection Supervisor (EDPS). (2019). Introduction to the hash function as a personal data pseudonymisation technique. Retrieved from: https://edps.europa.eu/sites/edp/files/publication/19-1030 aepd-edps paper hash final en.pdf [accessed: 10 March 2020].

[11]. Zheng, Y., Pieprzyk, J., \& Seberry, J. (1992, December). HAVAL - a one-way hashing algorithm with variable length of output. In International workshop on the theory and application of cryptographic techniques (pp. 81-104). Springer, Berlin, Heidelberg.

[12]. Mittmann, J. (2005). One-Way Encryption and Message Authentication. Retrieved from: http://wwwmayr.in.tum.de/konferenzen/Jass05/course s/1/papers/mittmann paper.pdf [accessed: 20 January 2020].

[13]. Lee, M., Love, E., \& Wascher, E. (2006). Linear Algebra of Magic Squares. Undergraduate Research, Central Michigan University, Mount Pleasant, Mich, USA.

[14]. Gharib, S., Ali, S. R., Khan, R., \& Munir, N. (2015). System of Linear Equations, Guassian Elimination. Global Journal of Computer Science and Technology.

[15]. Pandey, N. (2012). Secure Communication Scheme with Magic Square. Journal of Global Research in Computer Science, 3(12), 12-14.

[16]. Noaman, M. A. (2013). A VHDL model for implementation of MD5 hash algorithm. Engineering and Technology Journal, 31(6 Part (A) Engineering), 1107-1116.

[17]. Noroozi, E., Daud, S. M., \& Sabouhi, A. (2013). Secure digital signature schemes based on hash functions. International Journal of Innovative Technology and Exploring Engineering (IJITEE), 2(4), 321-325. 